\title{
Capitalismo verde y energías "limpias": Costa Rica como laboratorio mundial de descarbonización
}

\author{
Green capitalism and "clean" energies: Costa Rica as a "global \\ decarbonization laboratory"
}

\author{
Alberto Gutiérrez Arguedas \\ Universidad de Costa Rica \\ San José, Costa Rica \\ alguar48@gmail.com
}

\begin{abstract}
RESUMEN. En la última década, se ha construido un imaginario de Costa Rica como un país líder en el campo de las energías "limpias" y renovables y la lucha contra el cambio climático. El presente artículo se propone reflexionar acerca de la construcción de este imaginario, el cual ha alcanzado su máxima expresión a través del lanzamiento, en febrero de 2019, del Plan Nacional de Descarbonización (PND), promovido explícitamente como una forma de convertir al país en "laboratorio mundial de descarbonización". Se argumenta que la imagen internacional de Costa Rica como país de energías "limpias" está inscrita en un contexto de gobernanza mundial del cambio climático, que, desde sus orígenes en la década de 1990, ha estado dominado por un paradigma que busca compatibilizar la cuestión ambiental/climática con el pensamiento desarrollista y economicista de mercado: el capitalismo verde. Asimismo, se plantea la idea que Costa Rica desempeña un papel estratégico como "eco-laboratorio neoliberal", escenario de experimentación de formas innovadoras de gobernanza ambiental basadas en el mercado, del cual la descarbonización representa el más elocuente ejemplo.
\end{abstract}

PALABRAS CLAVE. Capitalismo verde; energías renovables; descarbonización; Costa Rica; excepcionalismo verde.

Este es un artículo de acceso abierto publicado bajo los términos de la Licencia Creative Commons 4.0 Internacional Atribución-NoComercial-SinDerivadas. 
ABSTRACT. In the last decade, it has been built an imaginary of Costa Rica as a leader in "clean"/renewable energies, as well as in the fight against climate change. This article aims to reflect on the construction of this imaginary, which has reached its maximum expression through the launch, in February 2019, of the National Decarbonization Plan (PND, in Spanish), explicitly promoted as a way of turning the country into a "global decarbonization laboratory". It is argued that the international image of Costa Rica regarding "clean" energy country is inscribed in a context of global governance of climate change, which, since its origins in the 1990s, has been dominated by a paradigm that seeks to reconcile the environmental/ climatic issue with the developmentalist and economistic market thinking: green capitalism. Likewise, it is asserted that Costa Rica plays a strategic role as a "neoliberal eco-laboratory", a place for experimentation of innovative forms of market-based environmental governance, of which decarbonization represents the clearest example.

KEYWORDS. Green capitalism, renewable energies; decarbonization; Costa Rica; green excepionalism.

\section{INTRODUCCIÓN}

El excepcionalismo verde costarricense - es decir, el imaginario que representa a Costa Rica como un país ejemplar en materia de gestión ambiental y sustentabilidad - se articula a través de varios ejes, uno de ellos, la producción de energía eléctrica a partir de fuentes renovables, comúnmente llamadas de "energías limpias ${ }^{1 "}$. Este artículo reflexiona y aporta elementos para comprender de qué manera, desde qué lugares y con qué propósitos se ha construido esta imagen internacional de Costa Rica como un país líder en la producción de energías "limpias", en particular, durante la última década.

La temática para discutir en este trabajo implica un diálogo entre diferentes escalas geográficas y políticas. Como se verá, la noción misma de energías "limpias" está inscrita y adquiere sentido en un contexto de gobernanza mundial del cambio climático, en el cual la producción de energías renovables ha sido promovida como

1 En el mainstream del debate ambiental, se utiliza el término "energías limpias" como sinónimo de energías renovables, es decir, aquellas que no provienen de combustibles fósiles. Se argumenta que esta subsunción de ambos términos es imprecisa, entre otras razones, porque la explotación de energías renovables también implica un conjunto de impactos socioambientales negativos. Por este motivo, a lo largo del texto se hace referencia al término energías limpias entre comillas. 
medida para reducir la emisión de gases de efecto invernadero, causantes de alteraciones climáticas. El primer apartado del texto hace una lectura crítica de este esquema de gobernanza global del clima, argumentando que el mismo ha estado dominado - desde sus orígenes en la década de 1990 - por un paradigma que busca compatibilizar la cuestión ambiental/climática con el pensamiento desarrollista y economicista de mercado, el cual denominamos aquí capitalismo verde.

El segundo apartado discute acerca de la construcción del imaginario de Costa Rica como país líder en energías "limpias" / renovables. En un primer momento, se sitúa este imaginario como un vector y un pilar dentro de otro más amplio, denominado excepcionalismo verde. En un segundo momento, se analiza el papel estratégico que desempeña Costa Rica en la gobernanza mundial del clima, el cual ha alcanzado su máxima expresión a raíz del lanzamiento, en febrero de 2019, del Plan Nacional de Descarbonización (PND). Se argumenta que, más allá de una simple política pública de alcance nacional, el PND ha tenido un carácter predominantemente mediático y performativo, el cual ha sido concebido y promovido explícitamente como una forma de convertir al país en un "laboratorio mundial de descarbonización". Asimismo, se discute la noción de Costa Rica como un "eco-laboratorio neoliberal", es decir, escenario de experimentación de formas innovadoras de gobernanza ambiental basadas en el mercado.

En un tercer momento, se interpela el imaginario de las energías "limpias" / renovables, contrastándolo con la realidad nacional, marcada por tensiones, disputas y conflictos entre diferentes actores alrededor de la producción energética. Entre estos, ocupan un lugar importante las tensiones entre una gestión pública o privada del sector eléctrico y los procesos de lucha comunal en defensa de los ríos, contra la instalación de proyectos hidroeléctricos, los cuales cuestionan directamente la idea de la hidroelectricidad - fundamental para la generación de electricidad en Costa Rica - como energía "limpia".

El texto finaliza con algunas reflexiones en relación con el desafío urgente de transformar la matriz energética mundial - basada mayoritariamente en combustibles fósiles y causante de una grave crisis climática - hacia formas de producción y consumo de energía que sean social y ambientalmente justas y sustentables. En ese sentido, se sustenta la tesis que las energías renovables pueden re- 
presentar una valiosa alternativa, sin embargo, que se torna insuficiente si no se revisan al mismo tiempo el modelo de desarrollo, los patrones de consumo y las relaciones de poder dominantes.

Desde el punto de vista metodológico, este trabajo se realizó esencialmente a partir de revisión de literatura y fuentes de prensa, usando una perspectiva basada en la ecología política. Asimismo, algunas de las reflexiones que aquí se comparten están inspiradas y se han visto enriquecidas a partir de discusiones académicas colectivas en el seno del Eje Naturaleza y Poder, del Centro de Investigación y Estudios Políticos (CIEP) de la Universidad de Costa Rica.

Agradezco a todas las personas que, directa o indirectamente, contribuyeron para que este trabajo pudiera hacerse realidad. En primer lugar, a todo el personal del Centro de Investigación y Estudios Políticos, en particular a las y los colegas vinculados al Eje Naturaleza y Poder, que me han proporcionado la valiosa oportunidad de trabajar en un ambiente estimulante y respetuoso. Su talento y dedicación han sido una gran fuente de inspiración. A todos aquellos compañeros y compañeras, dentro y fuera de la universidad, que luchan por otros mundos posibles, más sustentables, justos y generosos.

\section{CAPITALISMO VERDE, GOBERNANZA MUNDIAL DEL CAMBIO CLIMÁTICO Y ENERGÍAS “LIMPIAS"}

Las décadas de 1960 y 1970 fueron escenario de politización e institucionalización del tema ambiental a escala mundial. Si bien los problemas y desafíos derivados de la relación sociedad(es)naturaleza han estado presentes en diferentes contextos a lo largo de la historia humana, a partir de este momento "lo ambiental" gana consistencia y se constituye como un campo en sí mismo. Comúnmente se considera como hito histórico de esta institucionalización del ambiente la realización, en 1972, de la primera Conferencia de la Organización de las Naciones Unidas (ONU) sobre Medio Ambiente Humano - también conocida como "Cumbre de la Tierra" - durante la cual fue creado el Programa de Naciones Unidas sobre Medio Ambiente (PNUMA) (PortoGonçalves, 2011).

Desde estas primeras etapas, ya comenzaba a esbozarse un escenario complejo y heterogéneo en relación con el tema ambiental, compuesto por una multiplicidad de actores, perspectivas y posi- 
cionamientos político-ideológicos, en ocasiones con profundos antagonismos entre sí. De un lado, emergen una serie de movimientos y luchas que conciben la cuestión ambiental como inseparable de la dimensión social y política, confrontando las lógicas dominantes de organización del poder que operan simultáneamente en diferentes escalas. Dentro de esta perspectiva se puede mencionar, por ejemplo, aquello que Martínez Alier (2004) ha denominado de ecologismo popular, es decir, movimientos de base local - en su mayoría de comunidades indígenas y campesinas del Sur global - que luchan contra los impactos ambientales provocados por la reproducción globalizada del capital y la expansión de la frontera extractiva sobre sus territorios; o bien, el movimiento por justicia ambiental - surgido a partir de luchas de comunidades urbanas afrodescendientes en Estados Unidos contra el "racismo ambiental", posteriormente replicado y resignificado en otros países (Ascelrad, Mello y Bezerra, 2009; entre otros).

Por otro lado, conforme el tema ambiental se institucionaliza de formas más complejas a escala global, se fueron desarrollando y tomando fuerza perspectivas más alineadas con el statu quo, las cuales buscaban conciliar la protección del ambiente con el paradigma del desarrollo y su núcleo duro: el crecimiento económico. Según Ascelrad, Mello y Bezerra (2009), a partir de las décadas de 1980 y 1990 se desplegó un importante esfuerzo teórico por compatibilizar la cuestión ambiental con el pensamiento desarrollista y economicista de mercado, el cual coincide con la consolidación del modelo neoliberal a escala global. En otras palabras, la discusión ambiental fue incorporada dentro de la misma "utopía" liberal, de un bienestar alcanzable a partir del libre juego de las fuerzas del mercado. En concreto, lo que aquí denominamos como capitalismo verde hace referencia a ese paradigma pues busca conciliar las preocupaciones ambientales con la racionalidad económica mercantil, operando a través de un aparato ideológico-conceptual y de una arquitectura institucional específicos (Porto-Gonçalves, 2011; de Paula, 2013).

Desde el punto de vista ideológico, este ambientalismo de mercado se expresó principalmente a través del concepto de desarrollo sostenible. Este aparece por primera vez en el debate público en 1987, en un informe titulado "Nuestro Futuro Común", elaborado por una comisión internacional conformada por la ONU con el propósito de hacer un diagnóstico de la situación ambiental del planeta. Esta propuesta de "desarrollo sostenible" no cuestiona la 
idea de un crecimiento económico ilimitado - fundamento de la economía capitalista, y al contrario: sostiene que la mejor forma de responder a los retos planteados por la destrucción ambiental y la pobreza es mediante más crecimiento, preferiblemente con tasas anuales de entre $5 \%$ y $6 \%$ para el conjunto de países del Sur global, como recomienda el citado informe (Lander, 2011). Esta idea tuvo una extraordinaria eficacia política e ideológica y se constituyó como paradigma ecológico dominante en los principales espacios políticos, empresariales y agencias multilaterales. Asimismo, sirvió de plataforma y marco conceptual sobre el cual se realizaría, en 1992, la Conferencia sobre Medio Ambiente y Desarrollo de la ONU, llevada a cabo en Rio de Janeiro, Brasil, marco histórico de la gobernanza ambiental mundial.

Una de las principales características de este paradigma es que concibe y plantea la cuestión ambiental no como un problema social y político, sino como un problema técnico y de gestión. Desde esta perspectiva, la solución a los problemas ambientales radica en la implementación de tecnologías "limpias" que disminuyan los impactos ecológicos de la economía, así como en la incorporación de mecanismos de mercado en la gestión de los bienes naturales, con miras a una mayor "eco-eficiencia" (Mahnkopf, 2019). A nivel político, esta perspectiva se ha expresado a través de la privatización y mercantilización de los elementos de la naturaleza, es decir, de la creación de nuevos mercados asociados a la naturaleza, en el cual ocupa un lugar destacado el mercado de carbono (Lohman, 2012). En resumen, según de Paula (2013), mientras el capitalismo verde se refiere a transformaciones reales operadas en el capitalismo, en el sentido de adaptarse a una nueva división internacional del trabajo, a reordenamientos geopolíticos y en la relación Estado-mercado, así como a la asimilación del ambientalismo en el proceso de acumulación global, el desarrollo sostenible vendría a ser la ideología que busca dar legitimidad a ese movimiento real y concreto, de un nuevo ciclo de acumulación de capital que busca ocultar el despojo y devastación que le subyace.

En la última década, nuevos conceptos y formulaciones teóricas han venido a actualizar y dar continuidad a los planteamientos y posicionamiento político del capitalismo verde. Tal es el caso del par conceptual "economía verde/crecimiento verde", promovidos desde los principales organismos multilaterales de gobernanza ambiental, los cuales se han convertido, en la última década, en 
la respuesta dominante frente a la crisis ecológica y climática. De acuerdo con Seoane (2013), la economía verde surge como una propuesta para recuperar el crecimiento económico, en el contexto de la crisis financiera mundial de 2008 y sus preceptos han servido de referencia para la elaboración de políticas e instrumentos de gestión a nivel internacional, por ejemplo, el Acuerdo de París y los Objetivos del Desarrollo Sostenible (ODS) de la ONU. Entre sus principales promotores, se encuentra la Organización para la Cooperación y el Desarrollo Económicos (OCDE), el PNUMA, la Unión Europea y el Banco Mundial, así como algunos think tanks², cada uno con sus respectivos documentos e informes, en donde se exponen sus principios y propuestas (Unmüssig, 2012). Si bien no son lo mismo, la economía verde y el crecimiento verde se enmarcan en una misma corriente teórico-política, de ahí que se refiera a ambos de manera casi indistinta.

La tesis central de la economía verde es que el crecimiento económico (medido a través del producto interno bruto, PIB) es compatible con la ecología planetaria, y que es posible "desacoplar" el crecimiento del PIB del uso de recursos y de las emisiones de carbono, a un ritmo suficiente para revertir el cambio climático y el colapso ecológico (Hickel y Kallis, 2019). El mecanismo para alcanzarlo: invertir masivamente en innovaciones tecnológicas para mejorar la eficiencia ecológica de la economía, al mismo tiempo en que se debe estimular la valorización económica de los bienes naturales y su incorporación en mercados específicos, correspondiéndole a los gobiernos definir regulaciones y ofrecer incentivos para tales medidas (Mahnkopf, 2019). Más allá del discurso, la economía/ crecimiento verde ha recibido cuestionamientos desde diferentes sectores y se ha tornado objeto de un examen más riguroso, que ha arrojado luz sobre sus incoherencias e inconsistencias (ver: Lohman, 2012; Unmüssig, 2012; Hickel y Kallis, 2019).

Un campo en particular en el cual la perspectiva del capitalismo verde ocupa un lugar hegemónico es la gobernanza del cambio climático. Las bases de esta gobernanza fueron establecidas en la Conferencia de Rio en 1992, evento durante el cual se firmó la Convención Marco de Naciones Unidas sobre Cambio Climático (CMNUCC), que entró en vigor en 1994. Dentro de la CMNUCC la

2 Destaca el "Instituto de Crecimiento Verde Mundial" (Global Green Growth Institute -GGGI-), fundado en 2012, con sede en Seúl, Corea del Sur (para más información: www.gggi.org). 
máxima instancia que articula todos los países firmantes es la Conferencia de las Partes (COP), cuya primera reunión se llevó a cabo en 1995 y, desde entonces, han sido realizadas una vez al año, en sedes rotativas. También vale mencionar, como antecedente, que en 1988 el PNUMA y la Organización Meteorológica Mundial (OMM) conformaron el Panel Intergubernamental sobre Cambio Climático (IPCC), el cual publicó su primer informe en 1990, convirtiéndose desde entonces en el organismo científico más reconocido para referirse a esta problemática (Palacio, 2013). Así se configura, en términos generales, la arquitectura institucional de la gobernanza del cambio climático a escala supranacional.

Un punto de referencia en la gobernanza climática es el Protocolo de Kioto, el cual fue negociado y adoptado en 1997 -durante la $3^{\circ}$ reunión de la COP, con el objetivo de reducir las emisiones globales de gases de efecto invernadero (GEI), sobre todo dióxido de carbono. Más allá de sus buenas intenciones, el Protocolo de Kioto fue pionero en el proceso de mercantilización del clima. En él terminó imponiéndose la perspectiva del capitalismo verde, a través del establecimiento de una serie de mecanismos "basados en el mercado" (market-based), tales como los "esquemas de implementación conjunta" (artículo 6) y los Mecanismos de Desarrollo Limpio (MDL) (artículo 12) (Aykut y Castro, 2017). Como parte de los esquemas de implementación conjunta, se creó la figura de los bonos o créditos de carbono, los cuales reconocen los derechos a emitir dióxido de carbono como un bien canjeable y con un precio establecido en un mercado específico (Seoane, 2013). A partir de ello, se ha configurado lo que Aykut y Castro (2017) denominan una "industria de mercados de carbono", compuesta por think tanks, asesores, inversionistas y organismos internacionales, los cuales suelen defender enérgicamente los mercados de carbono en las cumbres climáticas.

Desde entonces, la perspectiva del ambientalismo de mercado ha ocupado un lugar central en la gobernanza mundial del clima. Como resultado de este proceso es posible observar, de acuerdo con Moreno, Speich y Fuhr (2016), que el discurso dominante sobre cambio climático ha estado centrado en el "carbono". Es decir, concibe y representa la crisis climática como si esta fuera casi exclusivamente un problema de "exceso de emisiones" de dióxido de carbono en la atmósfera. Este discurso, por un lado, es reduccionista, porque traduce la inmensa complejidad de esta crisis a una única variable ("carbono" o "emisiones"), perdiendo de vista el conjunto 
de alteraciones socioambientales más amplio del cual forma parte. Por otro lado, tiene una orientación mercantil, porque a través de un sofisticado sistema de cuantificación universal del dióxido de carbono - conocido como la métrica del carbono - este puede ser medido y contabilizado y, de esta forma, ser poseído y comercializado en el mercado (Lohman, 2012). En otras palabras, la narrativa centrada en el carbono tiene una intencionalidad política.

Es precisamente esta perspectiva "carbono-céntrica" la que domina en el Acuerdo de París, otro punto de referencia de la gobernanza climática, de la misma envergadura política y simbólica del Protocolo de Kioto. Dicho acuerdo fue negociado y firmado por los 195 países miembro de la CMNUCC durante la $21^{\circ}$ reunión de la COP, realizada en París, Francia, en 2015. Luego de una revisión exhaustiva del texto del acuerdo, Aykut y Castro (2017, p. 182) observan que el término que más se repite, por mucho, es "emisiones" (mencionado 48 veces), mientras que otros temas de importancia crucial en la crisis climática apenas son mencionados (la palabra "energía" aparece tres veces, "renovables", una vez y "fósil", ninguna).

El Acuerdo de París representa un punto de referencia en varios aspectos. En primer lugar, a partir de este se consolida de la idea de "descarbonización" en el debate público, la cual ha pasado a ocupar un lugar dominante en los discursos y políticas sobre cambio climático desde entonces. Según Moreno, Speich y Fuhr (2016), este acuerdo afianzó la métrica del carbono en la agenda multilateral y estableció un horizonte de alineamiento de las políticas nacionales a un esquema global. Además, según observan Foyer, Aykut y Morena (2017), dicho acuerdo señala una tendencia a sustituir los acuerdos legalmente vinculantes (como el Protocolo de Kioto, por ejemplo) por métodos más "suaves" de gobernanza climática, basados en compromisos voluntarios y no vinculantes. Se trata de un "acuerdo performativo", prácticamente una declaración de buenas intenciones, cuya principal función, según sus promotores, es "enviar las señales adecuadas" para una acción climática decidida y decisiva. De esta manera, cada país establece objetivos de reducción de emisiones de manera independiente, conocidas como las "Contribuciones Previstas Determinadas a Nivel Nacional" (NDCs, por sus siglas en inglés).

Al igual que la noción de descarbonización, la idea de "energías limpias" -ampliamente utilizada en la opinión pública y las institu- 
ciones políticas como sinónimo de energías renovables- se origina a partir de este reduccionismo de carbono. Desde esta perspectiva, el único criterio para considerar un tipo de energía como "limpia" es si esta emite o no dióxido de carbono de forma directa sobre la atmósfera, ignorando deliberadamente otro tipo de impactos sociales y ecológicos que estas puedan provocar. El caso más notable es el de la hidroelectricidad, principal fuente de energía renovable utilizada a nivel mundial, la cual no solo ha provocado graves daños socioambientales, sino que ha suscitado un alto grado de tensión y conflictividad en aquellos territorios y comunidades donde se han instalado-o se pretenden instalar- proyectos de este tipo, fenómeno ampliamente documentado alrededor del mundo (McCully, 2004).

En el contexto de la gobernanza del cambio climático, las energías "limpias"/renovables han ganado notable visibilidad y protagonismo en el escenario político internacional, particularmente, en la última década. De acuerdo con un informe publicado por la Agencia Internacional de Energías Renovables (IRENA, 2019), las renovables "se han movido hacia el centro del paisaje energético global" (p.12) y han experimentado un crecimiento sin precedentes a lo largo de la última década, principalmente en energía eólica y solar. Entre las causas que han favorecido tal expansión, se mencionan avances tecnológicos recientes que han reducido significativamente los costos de producción, un volumen de inversiones cada vez mayor, así como la promulgación de leyes y regulaciones para estimular su desarrollo, tanto a escala nacional como supranacional. Según el citado informe está en curso una "transición energética global" hacia las renovables, aseveración que podría considerarse demasiado optimista, tomando en consideración la centralidad político-económica del sector de los combustibles fósiles (80\% del consumo global de energía), así como el papel aún marginal de las renovables en la matriz energética mundial ( $9 \%$ del total) (Aykut y Castro, 2017).

Asimismo, es posible observar que la promoción de energías "limpias" / renovables por parte de organismos multilaterales, grandes ONG, think tanks, gobiernos nacionales, entre otros actores del mainstream ambiental, está pautada según los parámetros del capitalismo verde y la ortodoxia del crecimiento económico ilimitado. Por lo general, las propuestas emanadas desde estos actores insisten en la necesidad de aumentar exponencialmente la inversión y la capacidad tecnológica para explotar energías renovables, mien- 
tras que en ningún momento se plantea la posibilidad de definir políticas o estrategias para el descrecimiento, o bien, para establecer límites a los grandes contaminadores y consumidores de energía (ver, por ejemplo, WWF, 2014; Asturias y Arias, 2016; IRENA, 2019). En ocasiones, inclusive, puede notarse una correlación entre la promoción de las energías "limpias" y el impulso de reformas de corte neoliberal, como queda evidente en el informe de IRENA (2019), el cual aboga por "intervenciones políticas para estimular la diversificación energética", las cuales incluyen "disciplina fiscal y monetaria, inversión en capital humano e infraestructura y apoyo al sector privado" (p. 35).

Una vez descrito y caracterizado, a grandes rasgos, el paradigma del capitalismo verde y sus manifestaciones específicas en el campo de la gobernanza del cambio climático y las energías renovables, en el siguiente apartado se hará referencia al papel político y simbólico de Costa Rica dentro de este esquema de gobernanza ambiental y climática basado en el mercado.

\section{COSTA RICA: “LÍDER EN ENERGÍAS “LIMPIAS” Y "LABORATORIO MUNDIAL DE DESCARBONIZACIÓN"}

\section{Energías "limpias" / renovables: pilar del excepcionalismo verde costarricense}

Como ya se mencionó, la producción de energía eléctrica a partir de fuentes renovables constituye uno de los pilares sobre los cuales se sostiene el excepcionalismo verde costarricense. Es decir, no es un fenómeno aislado, sino que se articula dentro de un esquema más amplio y complejo el cual, a su vez, le precede.

En términos generales, se puede identificar los orígenes del excepcionalismo verde costarricense a partir del establecimiento de un sistema nacional de áreas protegidas, el cual experimentó una rápida expansión a partir de la década de 1970. De acuerdo con Evans (1999), en pocos años el sistema para la conservación comenzó a ganar prestigio y visibilidad internacional, convirtiéndose desde entonces en un referente mundial en este campo. En buena medida, la institucionalización de esta política estatal se dio como resultado de la presión ejercida por un joven sector conservacionis- 
ta, de matriz mayoritariamente académica. De acuerdo con Herrera (2013), este sector recibió fuerte influencia de corrientes ambientalistas provenientes de los Estados Unidos de tipo "culto a lo silvestre", es decir, aquellas que abogan por la preservación de espacios naturales prístinos fuera de la intervención humana, mediante la creación de parques nacionales y reservas para la vida silvestre (Martínez Alier, 2004).

Por otra parte, a partir de las décadas de 1980 y 1990 se experimenta lo que Herrera (2013) ha denominado como un "giro hacia el ambientalismo de mercado" en Costa Rica. Evidentemente, este proceso guarda estrecha relación con el contexto político-ideológico a escala mundial en relación con el tema ambiental, es decir, con el ascenso y hegemonía del paradigma del desarrollo sostenible y el capitalismo verde. Sin embargo, al mismo tiempo, va aún más allá. La gestión ambiental costarricense no solamente recibió fuerte influencia de estas grandes corrientes globales, sino que se convirtió desde entonces en una pieza importante dentro de la dinámica de ese ambientalismo de mercado global, a nivel político y simbólico. Muestra de ello es el hecho que Costa Rica fue pionera y proactiva en la adopción de mecanismos de gestión ambiental basados en el mercado, a través de políticas y programas como Canje de Deuda por Naturaleza y Pago por Servicios Ambientales (PSA), ambos implementados en 1987 (Ramírez, 2017).

Al mismo tiempo, el tema ambiental -en su versión dominante del desarrollo sostenible- jugaría un papel clave en el proceso de neoliberalización en Costa Rica. De acuerdo con Ramírez (2017), políticas y programas como las mencionadas anteriormente fueron claves en la financierización de la gestión ambiental en el país, la cual, a su vez, se constituyó como un campo estratégico mediante el cual el Estado costarricense fortaleció sus vínculos con el mercado global. La más clara expresión de esta neoliberalización de la agenda ambiental fue la propuesta de un "desarrollo sostenible a la tica", el cual se constituyó como paradigma de discursos y acciones durante la administración de José María Figueres (1994-1998) (Monge, 2014). De acuerdo con Monge (2014), este supuso la implementación combinada de los preceptos generales del desarrollo sostenible con la profundización del neoliberalismo como esquema político-económico dominante a escala nacional, siendo además presentado como la continuación de la supuesta excepcionalidad histórica del país. 
Desde entonces, el tema ambiental se convierte en eje central de la política exterior costarricense y carta de presentación del país ante la comunidad internacional (Monge, 2014). En particular a partir de la década de 1990, se pone en marcha una sofisticada estrategia discursiva y mediática, la cual representa a Costa Rica, de manera sistemática, como un país caracterizado por una espectacular riqueza natural y ejemplar en gestión ambiental, con el objetivo de promocionarlo como polo de inversión extranjera y cooperación internacional, así como destino turístico ecológico a nivel mundial. En ese sentido, otro de los pilares del excepcionalismo verde ha sido el (eco)turismo, el cual ha sido en buena medida responsable de la construcción y propagación del imaginario, a través de un conjunto de campañas publicitarias direccionadas a visibilizar las bellezas naturales del país, tales como "Sin ingredientes artificiales" (1997) y, posteriormente, "Costa Rica Esencial" (2013), autodefinida en su página web como una "marca país" (ver Navarro en este volumen).

Estos son los antecedentes y el contexto general sobre los cuales se inscribe el imaginario de Costa Rica como país líder en energías "limpias", el cual se ha consolidado a partir de la última década. Incontables representaciones -en publicidad, reportajes periodísticos, informes técnicos, entre otros- continuamente describen y caracterizan el modelo de generación de energía eléctrica costarricense utilizando adjetivos como "limpio" y "sostenible", por el hecho de estar basado mayoritariamente en fuentes renovables. En ese sentido, uno de los documentos que mejor refleja este discurso es un informe del Instituto Costarricense de Electricidad -ICE- titulado "Costa Rica, matriz eléctrica: un modelo sostenible, único en el mundo" (ICE, 2015), el cual, al mismo tiempo en que expone una caracterización general del modelo eléctrico costarricense -en el pasado y el presente-, no escatima elogios al mismo, inclusive, anexando en su parte final una amplia selección de noticias periodísticas de medios internacionales, que aplauden los logros de Costa Rica en esta materia.

Del total de energía eléctrica producida en el país en 2019, un $69,18 \%$ correspondió con hidroelectricidad, 15,88\% energía eólica, $13,37 \%$ geotérmica, $0,85 \%$ térmica, $0,64 \%$ biomasa y $0,08 \%$ solar (ICE, 2019). Es decir, para ese año un 99,15\% de la energía eléctrica fue producida a partir de fuentes renovables, tendencia que se ha mantenido constante en el último trienio (99,67\% en 2017 y 98,6\% 
en 2018). No obstante, vale aclarar que estos porcentajes corresponden únicamente con energía eléctrica, la cual representa apenas una quinta parte $(20,3 \%)$ del consumo energético total del país. Si se toma en cuenta la energía en todas sus formas, es posible constatar que el modelo costarricense no difiere demasiado del promedio mundial, siendo que dos terceras partes $(66,4 \%)$ del consumo energético total corresponde con derivados de petróleo -principalmente asociados al sector transporte-, los cuales son importados en su totalidad (SEPSE, 2018). Sin desmeritar el importante logro que representa una matriz eléctrica casi totalmente basada en fuentes renovables -con recursos que se encuentran dentro del territorio nacional-, es necesario ubicar dicha matriz en contexto y darle su debida proporción.

Finalmente, es pertinente aclarar que la producción de energía eléctrica a partir de fuentes renovables no es algo nuevo en la historia de Costa Rica. Al contrario: desde que se inició esta actividad, a finales del siglo XIX, la generación eléctrica ha estado mayoritariamente basada en renovables, específicamente, en hidroelectricidad (Perry y Berry, 2016). Resulta interesante observar que, con el pasar del tiempo y en función de los valores dominantes en cada época, la hidroelectricidad se ha resignificado: primero considerada motor de "desarrollo nacional" (construcción de grandes represas del ICE y electrificación del territorio nacional, piezas clave en el proyecto estatal benefactor-desarrollista de la segunda mitad del siglo XX) y luego, como fuente de energía "limpia", en el contexto del desarrollo sostenible y el excepcionalismo verde. Es decir, el discurso de las energías "limpias" se articuló y complementó con un modelo de generación de energía eléctrica previamente existente, de matriz hídrica.

\section{"Laboratorio mundial de descarbonización": el papel estratégico de Costa Rica en la gobernanza del cambio climático}

Otro de los pilares sobre los cuales se sostiene el excepcionalismo verde es el papel protagónico que ha tenido Costa Rica en la gobernanza mundial del cambio climático. Importantes esfuerzos políticos y diplomáticos han sido desplegados, con el objetivo de posicionarlo como un país líder y ejemplo en la lucha contra el cambio climático, convirtiéndose en un elemento central de la "marca país" 
que es promocionada a nivel mundial. Una de las características distintivas de este discurso es el destacar cómo Costa Rica, a pesar de ser un pequeño país del Sur global, ha logrado tomar medidas y acciones decididas en pro del desarrollo sostenible, utilizando el prestigio que le proporcionan las energías renovables -así como su gestión ambiental en general- como una especie de autoridad moral para "guiar" a los demás países por ese camino.

Esta perspectiva la podemos encontrar, por ejemplo, en un informe del Fondo Mundial para la Naturaleza (WWF) sobre energías "limpias" en América Latina, en donde se destaca cómo "a pesar de su pequeño tamaño, Costa Rica da pasos de gigante y lidera con el ejemplo: uno 100\% sostenible. Es un modelo inspirador para la región" (WWF, 2014, p. 11). O bien, en el VII Plan Nacional de Energía del Ministerio de Ambiente y Energía (2015-2030), en el cual se reconoce que el aporte de Costa Rica en la lucha contra el cambio climático es reducido en términos cuantitativos, sin embargo, que "el Estado costarricense puede asumir una posición de avanzada, que tenga un efecto ejemplarizante en el contexto internacional" (MINAE, 2015a, p. 2).

Los principales agentes de ese discurso son un conglomerado de actores vinculados al establishment ambiental, a escala nacional y global: organismos internacionales, think tanks, ONG, cuerpos diplomáticos y gubernamentales y asociaciones de negocios, entre otros. De acuerdo con Foyer, Aykut y Morena (2017) alrededor de la gobernanza del cambio climático se ha conformado una especie de "comunidad climática", con sus propios códigos, prácticas y lenguajes, en donde se observa una dinámica de tipo "puerta giratoria", es decir, una fuerte circulación y rotación de individuos específicos entre esos diferentes espacios. Dicha "comunidad" articula de manera compleja diferentes escalas geográficas y políticas y tiene como máxima expresión los mega-eventos climáticos de la ONU, los cuales representan la infraestructura material de esa gobernanza global. Según los autores citados, en su reflexión sobre la COP21 , este evento no solamente representa un hito histórico en materia de gobernanza climática, sino también un momento y lugar en donde "lo global se localizó" (Foyer, Aykuy y Morena, 2017, p. 1).

Uno de los personajes más representativos y visibles de esta "comunidad climática" mundial es la política costarricense Christiana Figueres. Figueres ha sido miembro del equipo de negociación de Costa Rica en la CMNUCC desde 1995 y, en 2010, fue nombrada Se- 
cretaria General de dicha Convención, convirtiéndose en la primera persona de un país "subdesarrollado" en asumir dicho puesto. De acuerdo con el comunicado de prensa oficial de la ONU, "la Sra. Figueres es una líder internacional en el campo de las estrategias para abordar el cambio climático y aporta a este puesto por (...) su valiosa experiencia práctica en el sector público, el sector sin ánimo de lucro y el sector privado" (ONU, 2010). En efecto, además de su papel como figura pública y política, Figueres ha ocupado influyentes puestos en el sector privado a nivel internacional ${ }^{3}$, siendo una figura destacada, no solamente en la construcción de los mercados de carbono, sino del capitalismo verde mundial en general (Lohman, 2012). Podría decirse que personifica mejor que nadie el excepcionalismo verde costarricense, jugando un rol clave de articulación entre la escala nacional y la global.

Más allá de este personaje en específico, es posible observar la conformación de una especie de "diplomacia verde" costarricense. En junio de 2020, el hasta entonces Ministro de Ambiente y Energía, Carlos Manuel Rodríguez, renunció a su puesto en el Gobierno para asumir la presidencia del Fondo Mundial para el Medio Ambiente (Global Environmental Facility-GEF), siguiendo los pasos de Figueres y convirtiéndose en la primera persona de un "país en desarrollo" en asumir dicho puesto. El GEF es una entidad público-privada, con participación de agencias de la ONU, bancos multilaterales, gobiernos nacionales y ONG internacionales, la cual tiene como objetivo brindar financiamiento para proyectos "sostenibles" en países del Sur global. Desde su creación en 1992 - durante la Conferencia de Rio - el GEF ha entregado más de US $\$ 20,5$ billones en subvenciones y US\$ 112 billones en el co-financiamiento a más de 48.000 proyectos en 170 países. Según el comunicado oficial del Gobierno, el nombramiento de Rodríguez en el GEF constituye un "reconocimiento al legado y visión del país en materia ambiental" (Presidencia de la República, 2020).

La construcción de esta imagen internacional ha ido de la mano con la implementación de una serie de políticas y programas gubernamentales, a escala nacional. Entre estas se puede mencionar

3 Según Lohman (2012), Figueres ha sido asesora superior de C-Quest Capital (empresa de financiamiento de carbono), asesora de cambio climático para Endesa (empresa energética española) y vicepresidenta del comité de calificación de carbono Rating (firma privada que aplica los criterios de clasificación crediticia para los activos del carbono). 
la iniciativa presidencial "Paz con la Naturaleza", creada en 2007 en el gobierno de Óscar Arias, con el propósito de sistematizar las acciones relacionadas con el cambio climático. Bajo esta iniciativa, Costa Rica asume una serie de compromisos, tanto a nivel nacional como internacional: crear una Estrategia Nacional de Cambio Climático; alcanzar la "carbono neutralidad" (C-neutral) para 2021; aumentar la cobertura boscosa y las áreas protegidas; liderar una red internacional de países C-neutrales; impulsar la creación de un sistema de retribuciones financieras para países con bosques primarios e impulsar los mecanismos de canje de deuda por naturaleza (Porras, 2017). Asimismo, en 2010 se crea, mediante Decreto Ejecutivo, la Dirección Nacional de Cambio Climático (DNCC), dentro del MINAE. De esta manera, el Estado costarricense conforma una arquitectura institucional específica en el tema de cambio climático, estrechamente conectada con e influenciada por los centros de la gobernanza ambiental mundial.

En este contexto se enmarca el Plan Nacional de Descarbonización (PND), el cual fue lanzado por el Gobierno de Costa Rica -a través de la DNCC/MINAE- en febrero de 2019, llevando a su máxima expresión el imaginario de país líder en la lucha contra el cambio climático. El lanzamiento del PND tuvo un fuerte carácter mediático y performativo, recibiendo amplia atención, cobertura y reconocimiento internacional. Líderes mundiales celebraron la iniciativa del gobierno costarricense y se refirieron al tema con un gran optimismo: "Costa Rica continúa su papel como líder mundial en ayudar a resolver la crisis climática" (Al Gore); "Plan de Descarbonización será una guía para cumplir el Acuerdo de París y la Agenda 2030" (Pedro Sánchez); "permanente compromiso de Costa Rica con el medio ambiente" (Michelle Bachelet); "es un hito global, que evidencia que un cambio de paradigma es necesario y posible" (Javier Manzanares, del Fondo Verde para el Clima); "Costa Rica está mostrando el liderazgo que necesitamos, los negocios con visión de futuro están listos para invertir e innovar a su lado" (Steve Howard, líder en "negocios sostenibles"), entre otros (El País C.R., 2019).

En sentido estricto, dicho Plan corresponde con los compromisos de Costa Rica en el marco del Acuerdo de París ("NDC") y comprende un conjunto de acciones estratégicas para potenciar la descarbonización de la economía costarricense en el largo plazo, definiendo para ello diez ejes y ocho estrategias transversales, cada uno con objetivos y metas específicos. Los diez ejes son: (1) "movi- 
lidad sostenible y transporte público"; (2) "transporte liviano cero emisiones"; (3) "transporte de carga eficiente"; (4) "energía eléctrica renovable a costo competitivo"; (5) "edificaciones sostenibles y de bajas emisiones"; (6) "sector industrial de bajas emisiones"; (7) "gestión integral de residuos"; (8) "sistemas agroalimentarios bajos en carbono"; (9) "modelo ganadero bajo en emisiones" y (10) "gestión de territorios con soluciones basadas en la naturaleza" (Gobierno de Costa Rica, 2019). Conceptualmente, el PND está concebido y planteado desde la perspectiva de la economía/crecimiento verde, tal como está colocado desde el primer párrafo del documento: "Costa Rica aspira a ser una economía moderna, verde y libre de emisiones -y a fortalecer su liderazgo (...) Dentro de los grandes cambios que enfrenta la economía mundial, incluyendo la "cuarta revolución industrial", destaca la necesidad de transitar hacia una economía sostenible con un desarrollo económico que no dañe el capital natural; esta informará las inversiones en infraestructuras para ser competitivas" (p.3).

Asimismo, las referencias al PND han venido de la mano con un fuerte discurso nacionalista. Algunas figuras políticas hicieron una analogía directa entre la descarbonización y la abolición de las fuerzas armadas, entre estas, el Presidente Carlos Alvarado -"la lucha contra el cambio climático nos convoca hoy a dar un paso adelante, así como hace 70 años cuando abolimos nuestro ejército"- y la entonces Directora de la DNCC/MINAE, hoy Ministra de Ambiente, Andrea Meza -"el legado de nuestros antepasados fue la abolición del ejército y nuestro legado a las nuevas generaciones será la abolición de los combustibles fósiles"-. Ambas declaraciones fueron publicadas en las respectivas cuentas personales de Twitter, el 1 de diciembre de 2018, en conmemoración de los 70 años de la abolición del ejército en Costa Rica (Arana, 2018). Otra referencia nacionalista utilizada con frecuencia es la asociación entre el PND y el "Gobierno del Bicentenario" (2018-2022), por motivo de los dos siglos de independencia que se cumplen en 2021. No se trata de una política pública cualquiera, sino de una cargada de un fuerte valor simbólico y mediático.

Las críticas al PND no se han hecho esperar, principalmente desde el ecologismo social y sectores críticos de la academia. Esta perspectiva se puede encontrar, por ejemplo, en un artículo titulado "¿Descarbonizar sin descolonizar la naturaleza?" (Álvarez et. al, 2019), el cual señala las siguientes cuestiones: (a) a nivel con- 
ceptual general, no hay una definición clara de qué se entiende por descarbonización -y aún menos de las formas prácticas a través de las cuales esto se puede alcanzar-; (b) el Plan se impuso de forma vertical, sin un proceso de participación social y ciudadana; (c) no menciona no el cómo ni el dónde se obtendría la energía necesaria para electrificar el transporte; (d) presenta un sesgo urbano y de clase, con fuerte énfasis hacia los vehículos eléctricos privados -de un costo mucho mayor al de vehículos de combustión-; (e) más allá del transporte eléctrico, no revisa el modelo de ciudad en términos de especulación inmobiliaria y el boom de construcciones; (f) no se refiere al modelo agroexportador monocultivista dominante en el país, el cual es altamente dependiente de energía fósil, como parte del problema; (g) habla de "residuos" y no del consumismo, caracterizado por un acceso de desigual a recursos y por una generación desigual de residuos; entre otros.

Organizaciones ecologistas han hecho observaciones similares y también han elaborado propuestas para enfrentar la crisis climática. Por ejemplo, el grupo COECO-Ceiba -vinculado a la ONG ecologista Amigos de la Tierra- propone las siguientes acciones como parte de ese esfuerzo por descarbonizar la economía: (a) fortalecer la agroecología, para producir alimentos saludables a escala local y nacional, (b) promover y fortalecer el manejo comunitario de bosques, (c) mantener y reforzar la prohibición de exploración y explotación de petróleo y gas natural en el territorio nacional y (d) revisar los tratados y acuerdos de "libre comercio", que fomentan el transporte de productos agrícolas a largas distancias, con una fuerte huella de carbono (COECOCeiba, 2019). Por su parte, la Federación Ecologista Costarricense (FECON) establece una conexión directa entre la crisis climática y el modelo de agricultura comercial mundial, proponiendo incluir una moratoria a la expansión del monocultivo de la piña como parte de un Plan Nacional de Descarbonización (FECON, 2019). Ninguna de estas propuestas ha sido tomada en cuenta por parte del Gobierno.

El PND ha sido promocionado, de forma explícita, como una forma de convertir a Costa Rica en un "laboratorio mundial de descarbonización", expresión utilizada de manera recurrente por parte de miembros de entes gubernamentales, así como de instancias de la gobernanza ambiental mundial. No obstante, esta idea de convertir al país en un "laboratorio climático" ya venía tomando forma desde algunos años antes. Por ejemplo, en un documento del MINAE, 
publicado en setiembre de 2015, en vísperas de la COP-21, se lee: "Costa Rica procura convertirse en un laboratorio a escala nacional en el proceso de descarbonización profunda de la economía mundial, trabajando con la sociedad civil, el sector privado, la academia y la comunidad internacional para ese fin" (MINAE, 2015b, p. 2). Un año más tarde, durante la COP-22 -realizada en Marrakech, Marruecos, en 2016-, la delegación costarricense lanzó la propuesta de "posicionarse como país pionero donde puedan probarse ideas nuevas para limpiar la economía del planeta y convertirse en un laboratorio verde para luego exportar medidas exitosas a otras naciones" (Arguedas, 2016). Según sus promotores, Costa Rica podría jugar un papel de "puente" entre la tecnología desarrollada en el Norte global con su aplicación en "economías emergentes".

Por otra parte, al calor del lanzamiento del PND, el gobierno costarricense formalizó su intención de organizar, en condición de anfitriona, la COP-25, en 2019. Finalmente, dicha Conferencia fue llevada a cabo en Madrid, España, no obstante, como reconocimiento a este Plan, el país logró ser designado como sede de la reunión previa a la COP, conocida como "Pre-COP", realizada entre los días 8 a 10 de octubre de 2019, considerado el "evento ambiental más importante de su historia" (Garza, 2019). En otras palabras: la gobernanza global del clima se "localizó" en Costa Rica durante la Pre-COP, bajo la tónica dominante del capitalismo verde. Indicador de ello es el papel del Presidente Carlos Alvarado, quien durante su intervención en la inauguración del evento, así como en declaraciones brindadas a la prensa, afirmó que Costa Rica ganaría \$19,500 millones si logra cumplir con las metas del PND (Salas, 2019), y que el país recurrirá al endeudamiento para financiar las inversiones necesarias para desarrollar el Plan (Astorga, 2019).

En resumen, hemos visto cómo Costa Rica juega un papel estratégico en la gobernanza del cambio climático la cual, según Foyer, Aykut y Morena (2017) muestra en los últimos años una tendencia hacia una descentralización de su arquitectura institucional -más allá de la CMNUCC-, con mayor protagonismo y visibilidad de actores y escalas locales y nacionales, en contraste con el "globalismo" que tradicionalmente ha dominado este campo. Una idea en particular merece ser resaltada: más allá de la gobernanza del clima, pareciera ser que Costa Rica ha desempeñado un papel de "eco-laboratorio neoliberal" (NyP CIEP, 2019), es decir, escenario de 
experimentación de formas innovadoras de gobernanza ambiental basadas en el mercado, desde la década de 1980 hasta la fecha. La descarbonización representa el último y más elocuente ejemplo de esta tendencia. En palabras de Andrea Meza "Nuestro país quiere posicionarse como un laboratorio para la descarbonización de la economía. Somos un país pequeño que podemos hacer pilotos de innovación para exportar a otros países de América Latina, eso es lo que queremos" (Arana, 2018).

\section{Tensiones, conflictos y disputas alrededor las energías "limpias/renovables y el sector eléctrico}

Existe un contraste entre el imaginario dominante de las energías "limpias", el cual se presenta idílico y despolitizado, con una realidad nacional y local marcada por una serie de tensiones, conflictos y disputas relacionadas con la producción energética y el modelo eléctrico nacional. A grandes rasgos, pueden identificarse dos grandes ejes conflictividad social en este campo: la tensión alrededor de una gestión pública o privada del sector eléctrico y las luchas comunales contra proyectos de generación de energía, sobre todo, proyectos hidroeléctricos.

Con respecto al primero, vale mencionar que el sector eléctrico originó uno de los mayores conflictos sociales en la historia reciente de Costa Rica: la lucha contra el "Combo del ICE", entre 1998 y 2000. El "Combo" fue el nombre popular a un proyecto de ley impulsado por el gobierno de Miguel Ángel Rodríguez, que buscaba una privatización total y abrupta de la energía y las telecomunicaciones (Solís, 2002). Los principales actores que protagonizaron la oposición a esta iniciativa fueron sindicatos y organizaciones de trabajadores del sector público, sin embargo, con el tiempo se transformó en una lucha social multisectorial, con participación de una pluralidad de actores a escala nacional, entre ellos, el movimiento ecologista y organizaciones socioambientales de base comunitaria (Cartagena, 2010). Finalmente, la férrea oposición popular doblegó la iniciativa privatizadora, la cual fue retirada de la corriente legislativa en 2000.

No obstante, los intentos de privatización del sector eléctrico en Costa Rica van más allá de esta iniciativa en específico. Pioneras en este sentido fueron las llamadas "leyes de cogeneración" (No.7200 y 7508, de los años 1990 y 1995 respectivamente), mediante las cua- 
les se autorizó la generación de electricidad por parte de empresas privadas, bajo un esquema conocido como "cogeneración" o "generación eléctrica paralela", en el cual el ICE compra la electricidad generada en dichas plantas privadas. Lejos de ser un fenómeno aislado, estas iniciativas se enmarcan en un contexto más amplio de liberalización de los mercados eléctricos nacionales en Centroamérica, en el marco del ajuste estructural (GeoComunes, 2019). Sin embargo, a diferencia de los demás países de la región, donde las privatizaciones se dieron de manera casi total, en Costa Rica se dio una privatización parcial bajo ciertas regulaciones ${ }^{4}$ y conformando una especie de "modelo mixto", con participación de empresas públicas y privadas (Gutiérrez y Villalobos, 2020).

Posteriormente han sido planteadas otras iniciativas -en su mayoría, proyectos de ley- tendientes a aumentar el margen de participación privada en el sector eléctrico. Entre estas se pueden mencionar el proyecto de Ley General de Electricidad (gobierno de Óscar Arias, 2006-2010) y el proyecto de Ley de Contingencia Eléctrica (gobierno de Laura Chinchilla, 2010-2014), de los cuales ninguno logró avanzar, en buena medida, por la oposición social (Durán, 2014). De acuerdo con González (2013), dentro de los actores que se han pronunciado en favor de impulsar mayor participación privada en el sector - en foros públicos, comparecencias legislativas, conferencias, notas periodistas, entre otros medios - está la Unión Costarricense de Cámaras y Asociaciones del Sector Empresarial Privado (UCCAEP), la Asociación Costarricense de Productores de Energía (ACOPE), la Asociación Costarricense de Grandes Consumidores de Energía (ACOGRACE) y la Cámara de Industrias, así como algunos partidos políticos. La presión privatizadora ha sido sistemática, hasta la fecha.

El segundo eje de conflictividad guarda relación con el primero. A partir de las leyes de cogeneración se abrió un nuevo nicho de negocios, que fue rápidamente ocupado por un conjunto de empresas privadas, cuyos contratos de venta de electricidad al ICE les proporcionaron un amplio margen de ganancias (Álvarez, 2003). Esto, a su vez, provocó impactos territoriales concretos, en particular, una proliferación de represas nunca vista en la historia del país. Del total de 60 plantas hidroeléctricas actualmente en operación a

4 Según las leyes de cogeneración, la generación eléctrica privada no puede ser mayor al 30\% de la oferta eléctrica total y los proyectos de capital privado no deben ser mayores a los 50 megavatios -MW- de potencia, entre otras. 
nivel nacional, solamente en la década de 1990 fueron construidas un total de 22 (en promedio, más de dos por año, la mayoría privadas), modificando significativamente el mapa hidroeléctrico nacional (Gutiérrez y Villalobos, 2020). Al calor de la lucha contra el Combo ICE también se hicieron fuertes críticas y cuestionamientos a las leyes de cogeneración, por motivo de los privilegios desproporcionados otorgados a los generadores privados -cuyos negocios provienen de fondos públicos-, así como por los impactos socioambientales provocados por el represamiento de los ríos, en diferentes regiones del país (Durán, 2005).

A partir de la década de 1990 comienza a emerger una multiplicidad de luchas comunitarias en defensa de los ríos, contra la instalación de nuevos proyectos hidroeléctricos, lo cual podría interpretarse como una respuesta frente a la expansión acelerada y agresiva puesta en marcha en ese período (Gutiérrez, 2019). En investigación reciente, se realizó una sistematización y un mapeo de los diferentes casos de resistencia comunal contra represas y proyectos hidroeléctricos a escala nacional, dando como resultado una densa cartografía de luchas, distribuidas geográficamente en doce "núcleos de conflictividad". Podría decirse que este constituye uno de los principales ejes de conflictividad socioambiental en Costa Rica en las últimas décadas, colocando en cuestión la narrativa dominante que concibe la hidroelectricidad como energía "limpia". De hecho, a raíz de estas luchas las comunidades y sus organizaciones han logrado detener $-y$ en algunos casos archivar- un conjunto de proyectos que estaban planeados para ser construidos en diferentes regiones del país, de los cuales se identificó un total de 35 (Gutiérrez y Villalobos, 2020).

Asimismo, en las últimas dos décadas los diferentes procesos de lucha comunal contra proyectos hidroeléctricos han trascendido la escala local, articulándose entre sí y conformando un movimiento social en defensa de los ríos de alcance nacional, inclusive, con conexiones internacionales (Gutiérrez, 2019). En este proceso, las comunidades y sus organizaciones se han convertido en actores sociales y políticos en el debate público, visibilizando las afectaciones socioambientales provocadas por los proyectos hidroeléctricos

5 Los doce núcleos de conflictividad son: Upala, San Carlos-San Ramón, Sarapiquí, Guácimo, Coronado, Acosta, Zona de los Santos, Pacuare-Duchí-Turrialba, Pérez Zeledón-Buenos Aires, Coto Brus, Boruca-Diquís y Talamanca (Gutiérrez y Villalobos, 2020). 
y obligando a las autoridades a tomar en cuenta sus opiniones y perspectivas. En este sentido, un punto de referencia fue el Diálogo Nacional sobre el Sector Eléctrico, organizado por el gobierno de Luis Guillermo Solís entre octubre y diciembre de 2014, con el objetivo de proporcionar un espacio de diálogo y negociación, con miras a la elaboración de una nueva política energética nacional. De acuerdo con Durán (2015), a pesar de la desigualdad en la representación de los diferentes sectores, este espacio permitió un acercamiento inédito entre actores generalmente opuestos y representó para las organizaciones ecologistas y comunitarias -históricamente irrespetadas y excluidas en los procesos de toma de decisiones- una valiosa oportunidad para exponer críticas y ofrecer propuestas en esta materia.

Las discusiones en el seno del Diálogo Eléctrico Nacional sirvieron como insumo para la elaboración del VII Plan Nacional de Energía (2015-2030), alrededor de cuatro ejes: eficiencia energética, generación distribuida, optimización de la matriz eléctrica y aspectos socioambientales. Un tema en particular que merece destaque es que dicho Plan se plantea como objetivo estratégico la diversificación de la matriz eléctrica hacia energías renovables no convencionales (ERNC), como geotérmica, eólica, solar y biomasa, más allá de la tradicional hidroelectricidad (MINAE, 2015a). Este aspecto marca un punto de inflexión en la política nacional en materia de generación eléctrica, históricamente centrada en el desarrollo de grandes represas hidroeléctricas. De hecho, en los últimos cinco años se verifica una disminución significativa en la construcción de nuevas hidroeléctricas, en donde destaca la prohibición legal de construir represas en los ríos Pacuare y Savegre durante 25 años - mediante un decreto presidencial de salvaguarda ambiental emitido en 2015 - así como el caso del megaproyecto El Diquís, suspendido indefinidamente por el ICE en noviembre de 2018, entre otros (Durán, 2018). A manera de hipótesis, es razonable plantear que las luchas comunitarias contra represas terminaron teniendo repercusión en la política pública nacional, y que la diversificación de la matriz eléctrica hacia ERNC, en parte, fue resultado de la presión ejercida por el movimiento social en defensa de los ríos.

No obstante, el impulso a las ERNC vuelve a colocar sobre la mesa el debate (y la tensión) alrededor de una gestión pública o privada del sector eléctrico. De acuerdo con Chavarría (2016), quien realizó una sistematización de fuentes de prensa escrita so- 
bre el tema, es posible identificar una correlación entre el discurso privatizador y la apuesta en energías renovables o, en otras palabras, que las energías renovables han sido utilizadas como argumento para una mayor liberalización del sector eléctrico nacional. En efecto, la mayoría de los proyectos de generación eléctrica en ERNC pertenecen a empresas privadas, principalmente en energía eólica: del total de 16 plantas eólicas en operación en el país, 12 pertenecen a empresas privadas, dos a cooperativas de electrificación y dos a instituciones públicas, además de otros cuatro que están en fase de proyecto (GeoComunes, 2019). La única de las ERNC que escapa a esta tendencia es la geotermia, en donde se registran seis proyectos, todos operados por el ICE.

La misma correlación se puede establecer entre el discurso privatizador y la descarbonización. De acuerdo con un informe del Gobierno, el cual elabora un diagnóstico de los principales avances del PND al cumplirse un año desde su lanzamiento, "el trabajo colaborativo entre el sector público y privado se fortalece. El sector privado toma un liderazgo clave en la descarbonización, con el despliegue de acciones en reducción de emisiones y proyectos piloto" (Gobierno de Costa Rica, 2020, p. 3). Dentro de los proyectos piloto, se menciona una iniciativa llevada a cabo por las empresas Cemex (cementera) y FIFCO (alimentos y bebidas), en el cual coordinan para compartir viajes en transporte de carga y así reducir su huella de carbono. A partir de los planteamientos de Porto-Gonçalves (2011), se puede observar que esta es una característica típica del discurso del capitalismo verde: la creencia que los agentes principales en la transición a un mundo más sustentable serán las corporaciones, bajo la premisa que el mercado es la solución para cualquier problema, inclusive, los problemas ambientales.

\section{REFLEXIONES FINALES: MÁS ALLÁ DEL CAPITALISMO VERDE Y LAS ENERGÍAS “LIMPIAS"}

La temática abordada en el presente trabajo constituye uno de los principales desafíos teórico-políticos de nuestra época. Como demuestra una amplia evidencia científica, existe una relación directa entre el patrón civilizatorio moderno-capitalista, basado en el la explotación intensiva de combustibles fósiles, y la crisis climática, la cual constituye una de las más graves amenazas que enfrentan las sociedades humanas y la biosfera en este inicio del siglo XXI. 
De manera dramática y alarmante, la explotación de hidrocarburos sigue expandiendo sus fronteras y la concentración de gases de efecto invernadero en la atmósfera sigue aumentando cada día.

Frente a este escenario es posible identificar, a grandes rasgos, tres corrientes o posicionamientos políticos en relación con la crisis climática. En primer lugar, los "negacionistas climáticos", es decir, aquellos sectores que niegan la existencia de una crisis climática causada por el modelo energético fósil dominante. Esta corriente está representada principalmente por las grandes corporaciones del sector petrolero mundial, así como otras ramas que tienen estrechos vínculos con aquella, como la industria automovilística y la bélico-militar (Saxe-Fernández, 2019). Estos buscan mantener el ritmo actual de explotación de combustibles fósiles y representan una fuerza política de primer orden a nivel mundial, la cual ejerce un feroz cabildeo en los gobiernos nacionales, así como en la gobernanza mundial del clima. Sin lugar a dudas, el camino que marcan estos sectores representa un grave peligro a la humanidad y la ecología planetaria.

En segundo lugar, podemos ubicar a la perspectiva del capitalismo verde. Como hemos visto, el capitalismo verde reconoce la existencia de una crisis climática antropogénica, mayoritariamente asociada al patrón energético basado en fuentes fósiles que ha prevalecido desde la revolución industrial. Frente a este escenario, se ha conformado a partir de la década de 1990 una gobernanza mundial del clima, que ha tenido como uno de sus ejes centrales la promoción de energías renovables (también llamadas "limpias"), con el fin de disminuir la emisión de gases de efecto invernadero en la atmósfera. El capitalismo verde está representado por un conglomerado de actores, en diferentes escalas de poder, entre los cuales se puede mencionar: organismos internacionales (sobre todo, vinculados al Sistema de las Naciones Unidas), gobiernos nacionales, think tanks, asociaciones de negocios, ONG, entre otros. Desde esta perspectiva se han elaborado conceptos y formulaciones teóricas que ocupan un lugar hegemónico en el debate ambiental mundial -tales como desarrollo sostenible, economía verde y crecimiento verde-, las cuales suelen asumirse como verdades en sí mismas y pocas veces son objeto de un análisis crítico y riguroso.

Ciertamente, el capitalismo verde representa una opción más sensata y menos destructiva que el negacionismo climático petrolero. Sin embargo, al mismo tiempo, no es suficiente. Peor aún, po- 
dría decirse que forma parte del problema que pretende resolver. Según esta perspectiva, la solución a la crisis climática es aumentar exponencialmente la explotación de energías renovables, "bajas en emisiones", con el fin de sustituir el uso de combustibles fósiles. Este es el enfoque dominante, por ejemplo, en el Acuerdo de París, que coloca el tema de la descarbonización en el centro del debate. Sin embargo, la realidad es más compleja que la que muestra ese "optimismo verde". En efecto, en la última década ha crecido significativamente la explotación de energías renovables (IRENA, 2019), pero eso no significa que se esté sustituyendo a la energía fósil. Más bien, estas fuentes se están complementando y auxiliando, pues en dicho período también ha aumentado de manera sistemática la extracción y consumo de petróleo (BP, 2019), así como las emisiones de gases de efecto invernadero. Paradójicamente, se estima que la mitad de las emisiones históricas de gases de efecto invernadero se han generado en los últimos 25 años, es decir, desde que existe el aparato de gobernanza del clima, cuyos resultados pueden calificarse como decepcionantes (Saxe-Fernández, 2019).

El capitalismo verde no cuestiona la idea de un crecimiento económico ilimitado, más bien se alinea a esta y propone un acelerado crecimiento en la explotación de energías renovables, a un ritmo suficiente para reemplazar la energía fósil. Para ello será necesario llevar a cabo masivas inversiones en infraestructura, las cuales a su vez implican un consumo intensivo de energía y materiales y un fuerte impacto socioambiental, dentro de una lógica extractivista y desarrollista. Los mismos problemas de los combustibles fósiles se trasladan a metales y minerales, considerados "recursos estratégicos" para la industria de energías renovables y afines (Mahnkopf, 2019). Un caso destacado es el litio, un metal utilizado para fabricar paneles solares y baterías para vehículos eléctricos, cuyos yacimientos se han convertido en zonas de tensión y conflicto geopolítico. Más allá de su dimensión técnica/tecnológica, es necesario comprender la generación de energía en su contexto social, político y económico, así como en su materialidad territorial concreta. En ese sentido, considerando la complejidad y la gravedad de sus implicaciones, difícilmente estas energías puedan ser consideradas "limpias".

En tercer lugar, al margen de las primeras dos corrientes/enfoques, se encuentra un entramado complejo y plural de actores sociales, políticos y académicos que imaginan, proponen y construyen formas alternativas de enfrentar la crisis ecológica y climática. 
Se trata de una multiplicidad de perspectivas teórico-políticas que plantean, no solamente un cambio en el modelo energético dominante, sino un cambio en la forma en como nos relacionamos socialmente entre los seres humanos y con la naturaleza, otros horizontes de sentido para la vida. El buen vivir (Sumak Kawsay/Suma Qamaña), la justicia ambiental, climática y energética, el descrecimiento, el ecosocialismo, el ecofeminismo, la agroecología, entre otras, proporcionan valiosas reflexiones y conocimientos para la construcción de un mundo más sustentable, justo y generoso, lo cual implica necesariamente otras formas de producir y consumir energía, menos oligopólicas y más comunitarias, menos consumistas y más modestas. Las energías renovables podrían representar una valiosa alternativa, sin embargo, que se torna insuficiente si se mantienen prisioneras de la lógica mercantil y el lucro privado.

El imaginario de Costa Rica como "líder en energías limpias" y "laboratorio mundial de descarbonización" está inscrito en la segunda corriente, la del capitalismo verde. Aún más: a pesar de ser un pequeño país con un papel marginal en las relaciones de poder globales, el aparato tecno-político y simbólico de la "Costa Rica Verde" representa una pieza clave dentro del funcionamiento de ese ambientalismo de mercado global, cuya última y más elocuente expresión es el tema de la descarbonización. Sin dejar de reconocer los importantes logros que se han alcanzado en este país en materia ambiental, es necesario examinar el excepcionalismo verde costarricense desde una mirada más crítica y rigurosa. Es necesario señalar sus incoherencias, inconsistencias y contradicciones, identificar las relaciones de poder mediante las cuales se construye, sus agentes, discursos y finalidades políticas, sus ganadores y sus perdedores. Más allá de lo que muestra, también es necesario prestar atención en lo que oculta. A través del presente trabajo se ha procurado aportar a esa discusión.

\section{FUENTES CONSULTADAS}

Álvarez, et. al. (9 de octubre de 2019). ¿Descarbonizar sin descolonizar la naturaleza? Informa-Tico. Recuperado de: https://www.informa-tico. com/9-10-2019/descarbonizar-descolonizar-naturaleza.

Álvarez, M. (2003). Negocio millonario para compañías privadas. En: FECON. Revista Degeneración Eléctrica, (pp. 23-25). San José: Federación Costarricense para la Conservación. 
Arana, M. (8 de diciembre de 2018). Costa Rica quiere ser la anfitriona de la próxima COP-25. Climate Tracker. Recuperado de: http://climatetracker.org/costa-rica-quiere-ser-la-anfitriona-de-la-proxima-cop25/.

Arguedas, D. (2 de noviembre de 2016). Costa Rica se promocionará como laboratorio verde en cumbre climática. Ojo al Clima - Semanario Universidad. Recuperado de: https://ojoalclima.com/costa-rica-se-promocionara-laboratorio-verde-cumbre-climatica/\#: :text=Costa $\% 20$ Rica\%20se\%20promocionar\%C3\%A1\%20como\%20laboratorio\%20 verde $\% 20$ en $\% 20$ cumbre $\% 20$ clim $\%$ C3\%A1tica,-por $\% 20$ Diego $\% 20 \mathrm{Ar}$ guedas\&text $=\mathrm{El} \% 20$ concepto $\% 20$ propuesto $\% 20 \mathrm{es} \% 20$ ser,su $\% 20 \mathrm{apli}-$ caci $\%$ C3\%B3n $\% 20$ en $\% 20$ econom $\%$ C3\%ADas\%20emergentes.

Ascelrad, H., Mello, C., y Bezerra, G. (2009). O que é Justiça Ambiental. Rio de Janeiro: Garamond.

Astorga, L. (11 de octubre de 2019). Costa Rica recurrirá al endeudamiento para transformar y descarbonizar su economía. La Nación. Recuperado de: https://www.nacion.com/ciencia/medio-ambiente/costa-rica-recurrira-al-endeudamiento-para/COQO62VL3VGINAW7BCSY3OZ5PU/story/.

Asturias, J. y Arias, A. (2016). Impacto de la matriz energética en el desarrollo sostenible de América Latina y el Caribe. En: Brant, L. (Org.) Desarrollo sostenible y matriz energética en América Latina: la universalización del acceso a la energía limpia, (pp. 123-148). Belo Horizonte: Konrad Adenauer Stiftung/Centro de Direito Internacional.

Aykut, S. y Castro, M. (2017). The end of fossil fuels? Understanding the partial climatisation of global energy debates. En: Aykut, S., Foyer, J. y Morena, E. (eds.) Globalising the climate. COP21 and the Climatisation of Global Debates, (pp. 173-193). Oxford y Nueva York: Routledge.

BP (2019). BP Statistical Review of World Energy. 2019. (68th ed.). Londres: British Petroleum.

Cartagena, R. (2010). El ambientalismo y la lucha contra el combo del sector eléctrico (1998-2001). Revista de Ciencias Sociales. Universidad de Costa Rica, 2-3 (128-129), 49-61.

Chavarría, D. (2016). Las tecnologías de energía renovable en la prensa escrita costarricense. Revista de Ciencias Sociales, Universidad de Costa Rica, 3 (152), 27-47.

COECOCeiba (12 de julio de 2019). Descarbonizar la economía con soluciones reales. COECO-Ceiba. Recuperado de: http://www.coecoceiba. org/descarbonizar-la-economia-con-soluciones-reales/. 
de Paula, E. (2013). Capitalismo verde e transgressões: Amazônia no espelho de Caliban. Dourados: Editora UFGD.

Durán, O. (12 de noviembre de 2018). P.H. Diquís: triunfo social y oportunidad para cambiar el modelo eléctrico de Costa Rica. Informa-Tico. Recuperado de: https://www.informa-tico.com/12-11-2018/ph-diquis-triunfo-social-oportunidad-cambiar-modelo-electrico-costa-rica-0

Durán, O. (2015). Comunidades y ecologistas en el Diálogo Nacional sobre el Sector Eléctrico. Ambientico. 250-251, 4-11.

Durán, O. (2014). Contingencia y subasta privada del mercado eléctrico. Ambientico. 242, 44-51.

Durán, O. (2005). La estafa legal de la energía privada. Ambientico. 137, 10-14.

El País C.R. (24 de febrero de 2019). Líderes mundiales celebran Plan de Descarbonización de Costa Rica. El País. C.R. Recuperado el 24-082020 de: https://www.elpais.cr/2019/02/24/lideres-mundiales-celebran-plan-de-descarbonizacion-de-costa-rica/.

Evans, S. (1999). The Green Republic. A conservation history of Costa Rica. Austin: University of Texas Press.

FECON (13 de agosto de 2019). Moratoria a la expansión piñera debe incluirse en el Plan Nacional de Descarbonización. El País C.R. Recuperado de: https://www.elpais.cr/2019/08/13/fecon-moratoria-a-la-expansion-pinera-debe-incluirse-en-el-plan-nacional-de-descarbonizacion/.

Foyer, J., Aykut, S. y Morena, E. (2017). Introduction: COP21 and the "climatisation" of global debates. En: Aykut, S., Foyer, J. y Morena, E. (Eds.) Globalising the climate. COP21 and the Climatisation of Global Debates, (pp. 1-17). Oxford y Nueva York: Routledge.

Garza, J. (8 de octubre de 2019). Costa Rica alberga el evento ambiental más grande de su historia. La República. Recuperado de: https:// www.larepublica.net/noticia / costa-rica-alberga-el-evento-ambiental-mas-importante-de-su-historia\#: :text=Costa $\% 20$ Rica $\% 20$ alberga $\% 20 \mathrm{el} \% 20$ evento $\% 20$ ambiental $\% 20 \mathrm{~m} \% \mathrm{C3} \% \mathrm{~A} 1 \mathrm{~s} \% 20 \mathrm{import}-$ ante $\% 20$ de $\% 20$ su $\% 20$ historia,-Actividad $\% 20$ reunir $\%$ C3\%A1\%20 unas\&text $=$ Costa $\% 20$ Rica $\% 20$ alberga $\% 20$ desde $\% 20$ hoy,el $\% 20$ Centro\%20Nacional $\% 20 \mathrm{de} \% 20$ Convenciones.

GeoComunes (2019). Expansión de proyectos eléctricos en Centroamérica. El desarrollo de un sistema eléctrico regional fuera del control de los pueblos. 
Ciudad de México: Fundación Rosa Luxemburgo.

Gobierno de Costa Rica (2019). Plan Nacional de Descarbonización. Gobierno del Bicentenario, 2018-2022. San José: Gobierno de Costa Rica.

Gobierno de Costa Rica (2020). Plan Nacional de Descarbonización, 20182050. Avances 2019. San José: Gobierno de Costa Rica.

González, E. (2013). Posiciones de actores políticos y sociales acerca de políticas energéticas -ahorro, eficiencia y generación-. Análisis FES Costa Rica. 2, 1-35.

Gutiérrez, A. (2019). “¡Ríos para la vida!” Conflictos socioambientales por proyectos hidroeléctricos y el movimiento social en defensa de los ríos en Costa Rica. En: Alpízar F. (Ed.) Agua y Poder en Costa Rica, 1980-2017, (pp. 53-104). San José: Centro de Investigación y Estudios Políticos, Universidad de Costa Rica.

Gutiérrez, A. y Villalobos, D. (2020). Proyectos hidroeléctricos y resistencias comunitarias en defensa de los ríos en Costa Rica: un análisis geográfico. Cuadernos de Geografía: Revista Colombiana de Geografía. 29 (1), 133-151.

Herrera, M. (2013). Sustainable development in Costa Rica: a geographic critique. Journal of Latin American Geography, 12 (3),193-219.

Hickel, J. y Kallis, G. (2019). Is Green Growth Possible? New Political Economy. 25 (4): 469-486. doi: 10.1080/13563467.2019.1598964.

ICE (2015). Costa Rica, matriz eléctrica: un modelo sostenible, único en el mundo. San José: Instituto Costarricense de Electricidad.

ICE (2019). Generación y demanda. Informe 2019. San José: Centro Nacional de Control de Energía, Instituto Costarricense de Electricidad.

IRENA (2019). A New World. The geopolitics of energy transformation. Masdar: IRENA y Global Commission on the Geopolitics of Energy Transformation.

Lander, E. (2011). La Economía Verde: el lobo se viste con piel de cordero. Ámsterdam: Transnational Institute.

Lohman, L. (2012). La economía verde. En: Instituto de Estudios Ecologistas del Tercer Mundo. Capitalismo Verde. (pp. 9-44). Quito: Nina Comunicaciones.

Mahnkopf, B. (2019). Problemas y contradicciones del "capitalismo verde". En: Saxe-Fernández, J. (Coord.). Sociología política del colapso climático antropogénico. Capitalismo fósil, explotación de combustibles no convencionales y geopolítica de la energía. (pp. 131-155). Ciudad de México: 
Universidad Nacional Autónoma de México (UNAM).

Matínez Alier, J. (2004). El ecologismo de los pobres. Conflictos ambientales y lenguajes de valoración. Barcelona: Icaria/Antrazyt.

McCully, P. (2004). Ríos Silenciados. Ecología y política de las grandes represas. Buenos Aires: Editorial Proteger.

MINAE (2015a). VII Plan Nacional de Energía (2015-2030). San José: Ministerio de Ambiente y Energía.

MINAE (2015b). Contribución Prevista y Determinada a Nivel Nacional de Costa Rica. San José: Ministerio de Ambiente y Energía.

Monge, C. (2014). Desarrollo sostenible a la tica: geopolítica y ambiente en la administración Figueres Olsen (1994-1998). Revista Rupturas, 5 (1), 1-21.

Moreno, C., Speich, D. y Fuhr, L. (2016). A Métrica do Carbono: abstrações globais e epistemicídio ecológico. Rio de Janeiro: Fundación Heinrich Böll.

NyP CIEP (2019). Lecciones del eco-laboratorio neoliberal: monoculturas del desarrollo sostenible en Costa Rica. Propuesta para concursar por el Fondo Concursable para Grupos de Investigación. San José: Eje de Investigación Naturaleza y Poder, Centro de Investigación y Estudios Políticos, Universidad de Costa Rica (sin publicar).

ONU (2010). Christiana Figueres nombrada nueva Secretaria Ejecutiva de la CMNUCC. Comunicado de prensa. Nueva York: Organización de Naciones Unidas. Recuperado el 01-07-2020 de: https://unfccc.int/ files/press/news_room/press_releases_and_advisories/application/ pdf/100517_press_rel_new_es_spa.pdf

Palacio, G. (2013). Cambio climático, retórica política y crisis ambiental: una nueva interfase entre ciencias naturales y ciencias sociales. En: Postigo, J. (Ed.). Cambio climático, movimientos sociales y políticas públicas. Una vinculación necesaria, (pp- 51-74). Santiago de Chile: ICAL.

Perry, D. y Berry, K. (2016). Central American integration through infrastructure development: a case study of Costa Rica's hydropower. Regions \& Cohesion, 6 (1), 96-115.

Porras, M. (2017). Análisis crítico de la Política Nacional de Cambio Climático (PNCC). En: FECON/CoecoCeiba. ¿Laboratorio climático o dictadura del carbono? Un análisis de la financiarización de la naturaleza en Costa Rica, (pp- 5-16). San José: FECON/CoecoCeiba.

Porto-Gonçalves, C.W. (2011). A globalização da natureza e a natureza da globalização. (2a ed.) Rio de Janeiro: Civilização Brasileira.

Presidencia de la República (2 de junio de 2020). Nombramiento de Mi- 
nistro de Ambiente y Energía para liderar el Fondo Mundial para el Ambiente es reconocimiento al legado y visión país en materia ambiental. Presidencia de la República de Costa Rica. Recuperado el 12-072020 de: https://www.presidencia.go.cr/comunicados/2020/06/.

Ramírez, A. (2017). A political ecology of neoliberal multiculturalism. Social inclusion and market-based conservation in indigenous Costa Rica. (Tesis de Doctorado) International Institute of Social Studies, Erasmus University Rotterdam, Rotterdam.

Salas, Y. (2019). Carlos Alvarado en la PreCOP25: Costa Rica ganará $\$ 19,500$ millones con Plan de Descarbonización. La Nación. Recuperado de: https://www.nacion.com/ciencia/medio-ambiente/carlos-alvarado-costa-rica-ganara-1950/Q3G52K4ERFBFJDNH5XOD2YCD$\mathrm{VU} /$ story/.

Saxe-Fernández, J. (2019). Capitalismo histórico y contemporáneo (1750-presente): formación social vinculada al colapso climático antropogénico en curso. En: Saxe-Fernández, J. (coord.). Sociología política del colapso climático antropogénico. Capitalismo fósil, explotación de combustibles no convencionales y geopolítica de la energía (pp. 39-85). Ciudad de México: UNAM.

Seoane, J. (2013). Crisis climática: gestión sistémica, falsas soluciones y alternativas desde los pueblos. En: Seoane, J., Taddei, E. y Algranati, C. Extractivismo, despojo y crisis climática. Desafíos para los movimientos sociales y los proyectos emancipatorios de Nuestra América, (pp. 285-315). Buenos Aires: Herramienta/El Colectivo.

SEPSE (2018). Balance energético nacional de Costa Rica, período 2018. San José: Secretaría Ejecutiva de Planificación del Subsector Energía. Recuperado el 20-06-2020 de: https://sepse.go.cr/ciena/balances-energeticos/.

Solís, M. (2002). Entre el cambio y la tradición: el fracaso de la privatización de la energía y las telecomunicaciones en Costa Rica. Revista de Ciencias Sociales. Universidad de Costa Rica, 1 (95), 33-47.

Unmüssig, B. (2012). Economía verde: ¿la nueva fórmula mágica? Expectativas acerca de la Conferencia Rio +20. Ciudad de México: Fundación Heinrich Böll.

WWF. (2014). Líderes en Energía Limpia. Países Top en Energía Renovable en Latinoamérica. Gland: Fondo Mundial para la Vida Silvestre (WWF). 
ALBERTO GUTIÉRREZ ARGUEDAS es costarricense. Bachiller en Geografía por la Universidad de Costa Rica y Máster en Geografía por la Universidad Federal de Rio Grande do Norte (UFRN), Brasil. Docente e investigador de la Universidad de Costa Rica en la Sección de Historia y Geografía de la Sede de Occidente y el Centro de Investigación y Estudios Políticos (CIEP). 